\title{
Pengaruh Pengoperasian Jalan Tol Tegal-Pemalang Terhadap Kinerja Lalu Lintas Jalan Pantura Tegal-Pemalang
}

\author{
Isradias Mirajhusnita $^{(1)}$, Galuh Renggani Wilis ${ }^{(2)}$, Fita Ayunina Lathifah ${ }^{(3)}$ \\ (1,3) Teknik Sipil Universitas Pancasakti Tegal \\ (2) Teknik Mesin Universitas Pancasakti Tegal
}

\begin{abstract}
Abstrak
Jalan Tol Tegal-Pemalang direncanakan untuk mengurangi kemacetan di Jalan Pantura Tegal-Pemalang. Pembangunan Jalan Tol Tegal-Pemalang akan mempengaruhi kinerja lalu lintas di ruas Jalan Pantura Tegal-Pemalang. Oleh karena itu, dilakukan penelitian yang bertujuan untuk mengetahui seberapa besar dampak yang diakibatkan oleh pengoperasian jalan tol terhadap kinerja lalu lintas jalan pantura dengan membandingkan kinerja lalu lintas jalan pantura sebelum dan sesudah adanya jalan tol. Penelitian ini menggunakan data sekunder dan data primer. Metode yang digunakan adalah metode survei dengan mengumpulkan data di lapangan tentang kinerja lalu lintas jalan pantura sebelum dan sesudah adanya jalan tol kemudian menganalisisnya berdasarkan Manual Kapasitas Jalan Indonesia (MKJI) serta memprediksi pertumbuhan lalu lintas menggunakan Produk Domestik Regional Bruto (PDRB) menggunakan metode rumus bunga majemuk. Hasil penelitian ini menunjukan bahwa terjadi perubahan kinerja lalu lintas jalan pantura namun tidak signifikan. Menurut hasil analisis tingkat pelayaan sebelum adanya jalan tol memiliki nilai $F$ pada semua ruas jalan yang menunjukan ruas jalan tersebut mengalami kepadatan arus yang tinggi sehingga sering terjadi kemacetan saat jam sibuk. Setelah dibangunnya jalan tol terjadi peningkatan tingkat pelayanan pada ruas jalan pantura dengan nilai E pada ruas jalan arah Tegal dan nilai D pada ruas jalan arah Pemalang. Sedangkan tingkat pertumbuhan lalu lintas jalan pantura selama 10 tahun mendatang mengalami peningkatan sebesar 4266,85 smp/jam arus lalu lintas arah Tegal dan 4135,21 smp/jam arus lalu lintas arah Pemalang.
\end{abstract}

Kata Kunci: Kinerja Lalu Lintas, Manual Kapasitas Jalan Indonesia, Jalan Pantura dan Tingkat Pertumbuhan Lalu Lintas

\section{Pendahuluan}

Tegal merupakan salah satu wilayah yang dilalui oleh jalan pantura. Jalur Pantai Utara (Pantura) Jawa adalah ruas jalan nasional rute 1 dalam sistem jaringan jalan primer dengan fungsi sebagai jalan arteri primer, sepanjang $1.316 \mathrm{~km}$ yang menghubungkan lima provinsi di Pulau Jawa, yaitu Provinsi Banten, DKI Jakarta, Jawa Barat, Jawa Tengah dan Jawa Timur. Panjang Jalan Pantura Tegal $\pm 31,40 \quad \mathrm{Km} . \quad$ (Kep.Men.P.U.No:236A/ KPTS/1997)

Meningkatnya volume lalu lintas Ruas Jalan Pantura Tegal setiap tahunnya menyebabkan derajat kejenuhan meningkat sehingga terjadi beberapa masalah seperti kemacetan, kecelakaan, dan waktu tempuh perjalanan lebih lama. Untuk mengatasi tersebut, pemerintah membangun jalan tol. UndangUndang Nomor 38 tahun 2004 Tentang Jalan Tol menjelaskan bahwa jalan tol adalah jalan umum yang merupakan bagian sistem jaringan jalan dan sebagai jalan nasional yang penggunanya diwajibkan membayar tol.

Pembangunan Jalan Tol Tegal-Pemalang merupakan bagian dari jaringan Jalan Tol PejaganPemalang. Jalan Tol Pejagan-Pemalang adalah tol yang terbentang sepanjang 57,5 kilometer yang menghubungkan daerah Pejagan, Brebes dengan
Pemalang, Jawa Tengah. Jalan tol tersebut merupakan kelanjutan dari Jalan Tol Kanci-Pejagan yang menghubungkan Jakarta sampai dengan Batang. Jalan Tol Pejagan-Pemalang terbagi menjadi 4 (empat) seksi yaitu seksi I (Pejagan-Brebes Barat) sepanjang 14,2 km, seksi II (Brebes Barat-Brebes Timur) sepanjang $6 \mathrm{~km}$, seksi III (Brebes TimurTegal) sepanjang 10,4 km, dan Seksi IV (TegalPemalang) sepanjang 26,9 km. Jalan Tol TegalPemalang mulai diresmikan oleh Presiden Republik Indonesia Ke-7 Joko Widodo pada tanggal 9 November 2018. (id.m.wikipedia.org)

Dengan beroperasinya Jalan Tol Tegal-Pemalang secara langsung akan membawa perubahan arus lalu lintas di pantura karena masyarakat yang melakukan perjalanan jauh akan memilih menggunakan jalan tol daripada jalan pantura. Hal tersebut karena pertimbangan melalui jalan tol lebih cepat dan tidak mengalami hambatan kemacetan lalu lintas. Penelitian ini bertujuan untuk mengetahui berapa besar dampak yang diakibatkan oleh beroperasinya Jalan Tol Tegal-Pemalang terhadap kinerja lalu lintas Jalan Pantura Tegal-Pemalang. Dengan mengetahui kinerja lalu lintas, nantinya akan dibandingkan antara kinerja lalu lintas jalan pantura sebelum dan sesudah adanya jalan tol. 
Adapun tujuan dari penelitian ini adalah untuk mengetahui kinerja lalu lintas Jalan Pantura TegalPemalang sebelum dan sesudah adanya Jalan Tol Tegal-Pemalang, mengetahui perbandingan jumlah kendaraan yang melewati jalan tol dan jalan pantura dan bagaimana tingkat pertumbuhan lalu lintas jalan pantura selama 10 tahun mendatang.

\section{Metode}

Metode yang digunakan adalah metode survei, yaitu melakukan pengumpulan data tentang variabel suatu permasalahan dari lapangan kemudian menganalisa dengan perhitungan, sehingga dapat menghasilkan kesimpulan atas permasalahan yang ada.

Penelitian ini dilakukan pada hari kerja dan hari libur pukul 06.00-08.00 WIB (pagi), pukul 12.0014.00 WIB (siang) dan pukul 16.00-18.00 WIB (sore). Lokasi penelitian dilakukan pada ruas Jalan Pantura Tegal-Pemalang Desa Maribaya Kecamatan Kramat Kabupaten Tegal

Instrumen Penelitian (a)Formulir survei dan alat tulis, untuk pencatatan kendaraan, (b)Jam, untuk mengetahui awal dan akhir interval waktu yang digunakan, (c)Meteran, untuk mengukur jarak yang digunakan saat survei kecepatan dan mengukur lebar penampang jalan, (d)Hand counter, untuk menghitung jumlah kendaraan yang lewat, (e)Stopwatch, untuk mengetahui waktu tempuh, (f)Rompi Safety, untuk memberikan perlindungan pada saat survei.

Pencatatan volume lalu lintas dilaksanakan pada saat volume jam sibuk atau volume lalu lintas terpadat yang terjadi dan meliputi semua jenis kendaraan yang melintasi sepanjang Jalan Pantura Tegal-Pemalang Desa Maribaya Kecamatan Kramat Kabupaten Tegal. Cara pengisian formulir penelitian dibagi dalam interval waktu 15 menit. Setiap arah I (Tegal) \& arah II (Pemalang) dilakukan oleh dua surveyor yang mencatat kendaraan pada hari kerja dan hari libur. Pencatatan yang dilakukan sampai batas waktu yang telah ditentukan (per 15 menit), kemudian hasilnya dimasukan dalam formulir isian.

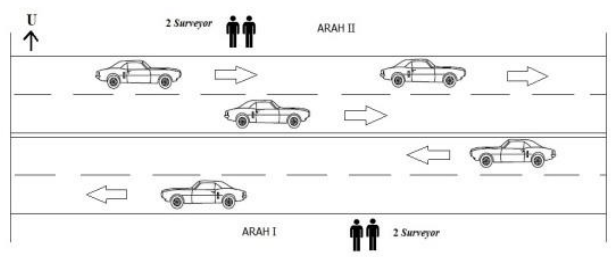

Gambar 1. Sketsa Survei Arus Lalu Lintas

Pengukuran kecepatan kendaraan setempat, Sampel yang perlu dipenuhi saat melakukan survei adalah :

a) Kendaraan yang paling depan dari suatu arus hendaknya diambil sebagai sampel dengan pertimbangan bahwa kendaraan kedua dan selanjutnya mempunyai kecepatan yang sama dan kemungkinan tidak dapat menyalip.

b) Sampel untuk mengambil kecepatan kendaraan dengan jarak $100 \mathrm{~m}$.

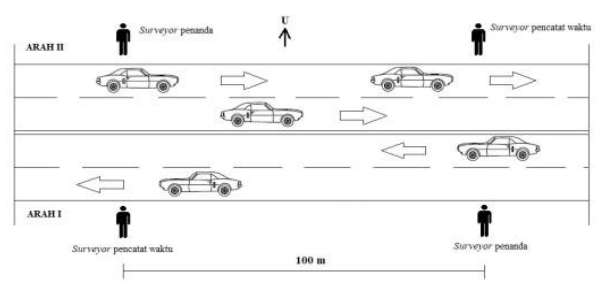

Gambar 2. Sketsa Survei Kecepatan Setempat

\subsection{Diagram Alur Penelitian}

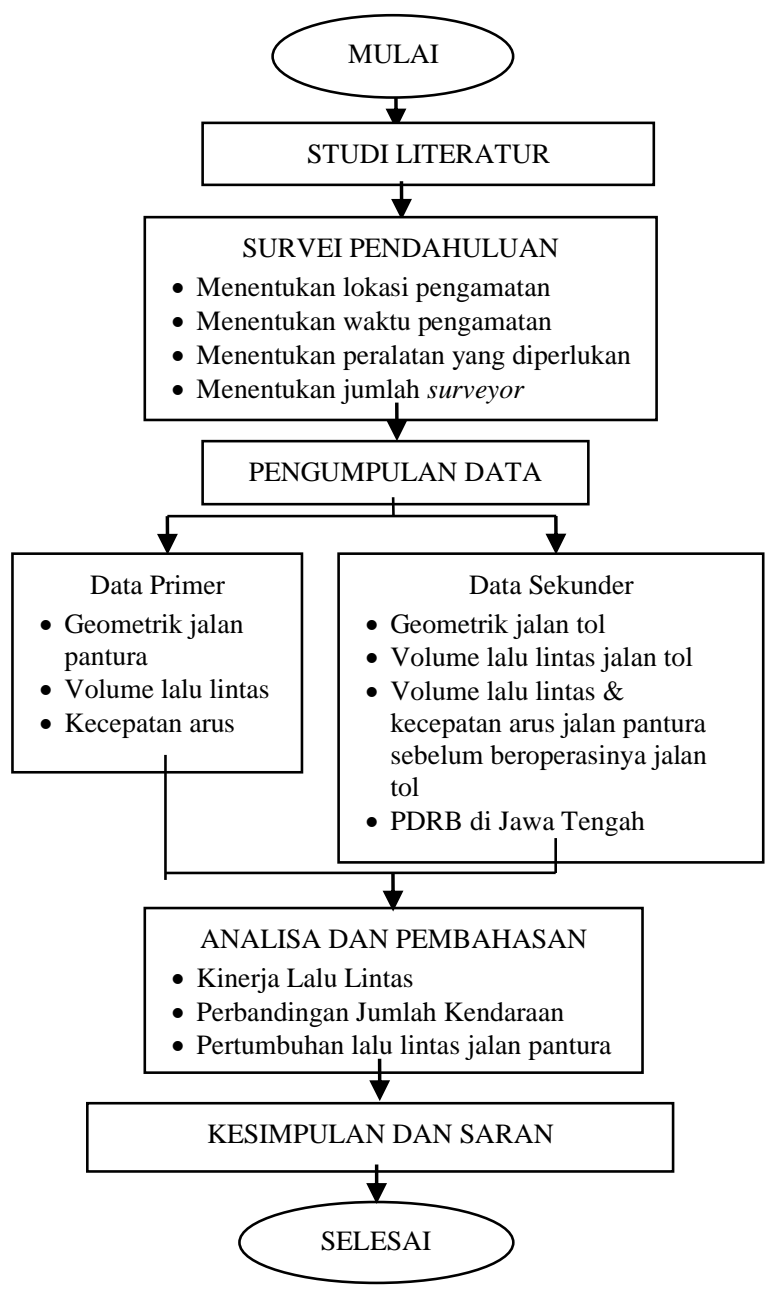

Gambar 3. Diagram Alir Penelitian

\section{Hasil dan Pembahasan}

Kinerja Lalu Lintas Jalan Pantura TegalPemalang Sebelum dan Sesudah Adanya Jalan Tol Tegal-Pemalang

Kapasitas Jalan Pantura

$\mathrm{C}_{\mathrm{O}}=$ Kapasitas dasar adalah 1.900 karena memiliki tipe 4 lajur 2 jalur terbagi 
$\mathrm{FC}_{\mathrm{W}}=$ Faktor penyesuaian kapasitas untuk lebar jalur arus lalu lintas adalah 1 karena lebar jalan pantura memiliki panjang 3,5

$\mathrm{FC}_{\mathrm{SP}}=$ Faktor penyesuaian untuk pemisah arah adalah 1 karena pemisah arah 50\%-50\%

$\mathrm{FC}_{\mathrm{SF}}=$ Faktor penyesuaian kapasitas untuk hambatan samping adalah 0,96 karena lebar bahu jalan $2 \mathrm{~m}$ dan kelas hambatan samping termasuk dalam kondisi hampir perkotaan dan pasar/kegiatan perdagangan sehingga termasuk pada kelas sangat tinggi

Sehingga :

$$
\begin{aligned}
\mathrm{C} & =\mathrm{C}_{\mathrm{O}} \times \mathrm{FC}_{\mathrm{W}} \times \mathrm{FC}_{\mathrm{SP}} \times \mathrm{FC}_{\mathrm{SF}} \\
& =1.900 \times 1 \times 1 \times 0,96 \\
& =1824 \mathrm{smp} / \mathrm{jam}
\end{aligned}
$$

Berdasarkan hasil perhitungan, dapat diketahui bahwa lokasi penelitian memiliki kapasitas jalan sebesar $1.824 \mathrm{smp} / \mathrm{jam}$

Kapasitas Jalan Tol

$\mathrm{C}_{\mathrm{O}}=$ Kapasitas dasar adalah 2.300 karena memiliki 4 lajur 2 jalur terbagi

$\mathrm{FC}_{\mathrm{W}}=$ Faktor penyesuaian kapasitas untuk lebar jalur arus lalu lintas adalah 1 karena lebar jalan pantura memiliki panjang 3,6 m

$\mathrm{FC}_{\mathrm{SP}}=$ Faktor penyesuaian untuk pemisah arah adalah 1 karena pemisah arah 50\%$50 \%$

Sehingga :

$$
\begin{aligned}
\mathrm{C} & =\mathrm{C}_{\mathrm{O}} \times \mathrm{FC}_{\mathrm{W}} \times \mathrm{FC}_{\mathrm{SP}} \\
& =2.300 \times 1 \times 1 \\
& =2300 \mathrm{smp} / \mathrm{jam}
\end{aligned}
$$

Berdasarkan hasil perhitungan, dapat diketahui

\begin{tabular}{|c|c|c|c|c|}
\hline \multirow[b]{2}{*}{$\begin{array}{c}\text { Arus Arah } \\
\text { ke- }\end{array}$} & \multirow{2}{*}{$\begin{array}{c}\text { Qtotal } \\
\text { smp/ } \\
\text { jam }\end{array}$} & \multicolumn{3}{|c|}{ LOS } \\
\hline & & Kapasita & $\begin{array}{c}\text { (Qtotal / } \\
\mathrm{C} \text { ) }\end{array}$ & Tingkat \\
\hline Tegal & 2303,6 & 1824 & 1,26 & $\mathrm{~F}$ \\
\hline Pemalang & 2249,2 & 1824 & 1,23 & $\mathrm{~F}$ \\
\hline
\end{tabular}
bahwa Jalan Tol Tegal-Pemalang memiliki kapasitas jalan sebesar $2.300 \mathrm{smp} / \mathrm{jam}$.

\section{Tingkat Pelayanan}

\section{Sebelum Tol}

Tabel 1. Tingkat Pelayanan Sebelum Tol

Sumber : Buku Kinerja Keselamatan Transportasi Kabupaten Tegal Tahun 2017

Menunjukkan tingkat pelayanan ruas Jalan Pantura Tegal-Pemalang sebelum beroperasinya jalan tol. Nilai derajat kejenuhan pada ruas jalan arah Tegal memiliki nilai derajat kejenuhan 1,26 sehingga ruas tersebut memiliki tingkat pelayanan $\mathrm{F}$ dengan karakteristik arus yang terhambat, kecepatan rendah, volume diatas kapasitas, dan banyak berhenti. Sedangkan pada ruas jalan arah Pemalang memiliki nilai derajat kejenuhan 1,23 sehingga ruas tersebut memiliki tingkat pelayanan yang sama seperti ruas jalan arah tegal yaitu $\mathrm{F}$ dengan karakteristik arus yang terhambat, kecepatan rendah, volume diatas kapasitas, dan banyak berhenti.

$>$ Sesudah Tol

Tabel 2. Tingkat Pelayanan Sesudah Tol

\begin{tabular}{ccccc}
\hline \multirow{2}{*}{$\begin{array}{c}\text { Arus Arah } \\
\text { ke- }\end{array}$} & $\begin{array}{c}\text { Qtotal } \\
\text { smp/ } \\
\text { jam }\end{array}$ & Kapasitas & \multicolumn{3}{c}{ LOS } \\
\cline { 4 - 5 } & $\begin{array}{c}\text { (total / }) \\
\text { C ) }\end{array}$ & Tingkat \\
\hline Tegal & 1753,5 & 1824 & 0,96 & E \\
Pemalang & 1699,4 & 1824 & 0,93 & D \\
\hline
\end{tabular}

Menunjukkan tingkat pelayanan ruas Jalan Pantura Tegal-Pemalang sesudah beroperasinya jalan tol. Nilai derajat kejenuhan pada ruas jalan arah Tegal memiliki nilai derajat kejenuhan 0,96 sehingga ruas tersebut memiliki tingkat pelayanan $\mathrm{E}$ dengan karakteristik arus tidak stabil, kecepatan rendah, volume padat atau mendekati kapasitas. Sedangkan pada ruas jalan arah Pemalang memiliki nilai derajat kejenuhan 0,93 sehingga ruas tersebut memiliki tingkat pelayanan yang sama seperti ruas jalan arah tegal yaitu D dengan karakteristik arus mendekati tidak stabil dan kecepatan dipengaruhi oleh lalu lintas.

\section{Kecepatan Setempat Arah Tegal}

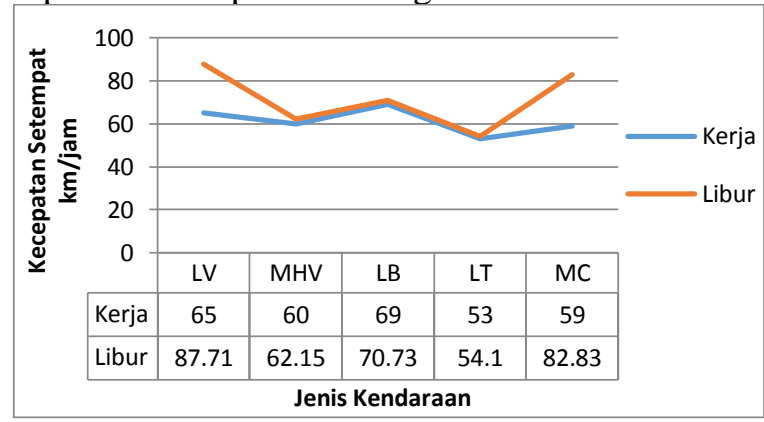

Gambar 3. Grafik Kecepatan Setempat Arah Tegal Sebelum Dan Sesudah Jalan Tol

Berdasarkan grafik diatas dapat diperoleh bahwa kecepatan setempat tertinggi Jalan Pantura TegalPemalang arah Tegal pada hari libur yaitu sesudah adanya jalan tol. Kecepatan tertinggi di dominasi oleh kendaraan ringan (LV) sebesar 87,71 km/jam.

Kecepatan Setempat Arah Pemalang

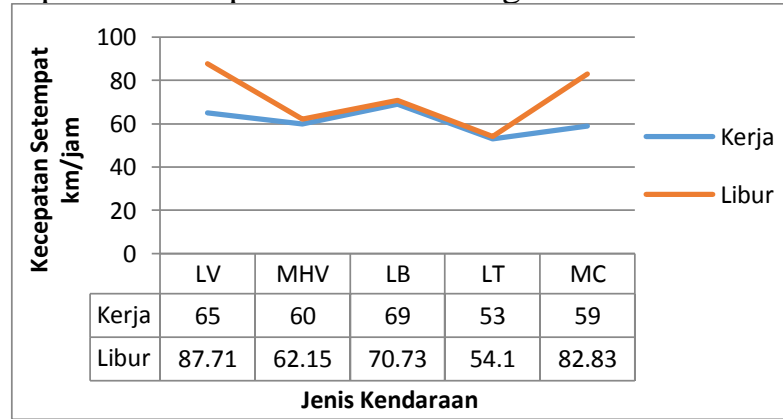


Gambar 4. Grafik Kecepatan Setempat Arah Pemalang Sebelum Dan Sesudah Jalan Tol

Berdasarkan grafik diatas dapat diperoleh bahwa kecepatan setempat tertinggi Jalan Pantura TegalPemalang arah Pemalang pada hari libur yaitu sesudah adanya jalan tol. Kecepatan tertinggi di dominasi oleh sepeda motor (MC) sebesar 74,81 $\mathrm{km} / \mathrm{jam}$.

\section{Perbandingan Jumlah Kendaraan yang Melewati Jalan Tol dan Jalan Pantura}

Tabel 3. Perbandingan Jumlah Kendaraan Jalan Tol Dan Jalan Pantura Hari Kerja

\begin{tabular}{ccc}
\hline No. & Hari Kerja & $\begin{array}{c}\text { Jumlah } \\
\text { Kendaraan } \\
\text { (kend/jam) }\end{array}$ \\
\hline 1 & Jalan Tol & 19.143 \\
2 & Jalan Pantura & 4.983 \\
\hline
\end{tabular}

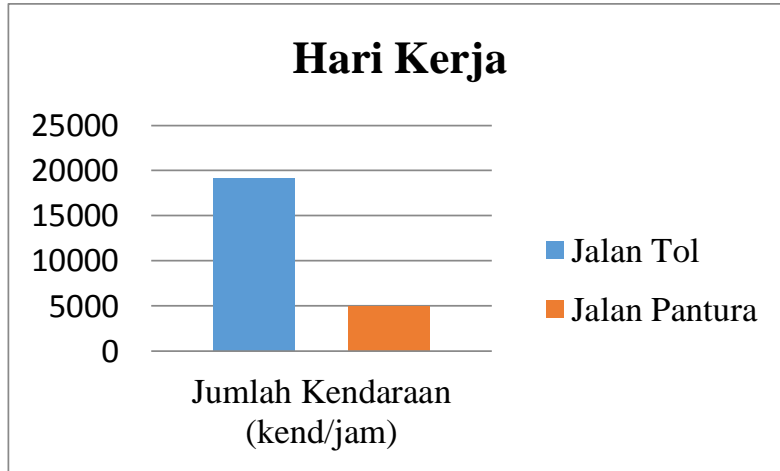

Gambar 5. Grafik Perbandingan Jumlah Kendaraan di Jalan Tol dan Jalan Pantura Pada Hari Kerja

Terlihat bahwa jumlah kendaraan yang melewati jalan tol lebih tinggi dari pada jalan pantura dengan presentase kendaraan yang melewati tol adalah $79,35 \%$ dihitung dari jumlah kendaraan yang lewat jalan tol (19.143 kend/jam) dibagi penjumlahan kendaraan yang lewat jalan tol ditambah kendaraan yang lewat jalan pantura (4.983 kend/jam). Sedangkan presentase kendaraan yang melewati jalan pantura adalah 20,65 \%. Kendaraan yang melewati jalan tol didominasi oleh kendaraan Golongan I yaitu mobil pribadi, pick up dan bus.

Tabel 4. Perbandingan Jumlah Kendaraan Jalan Tol Dan Jalan Pantura Hari Kerja

\begin{tabular}{ccc}
\hline No. & Hari Kerja & $\begin{array}{c}\text { Jumlah } \\
\text { Kendaraan } \\
\text { (kend/jam) }\end{array}$ \\
\hline 1 & Jalan Tol & 19.143 \\
2 & Jalan Pantura & 4.920 \\
\hline
\end{tabular}

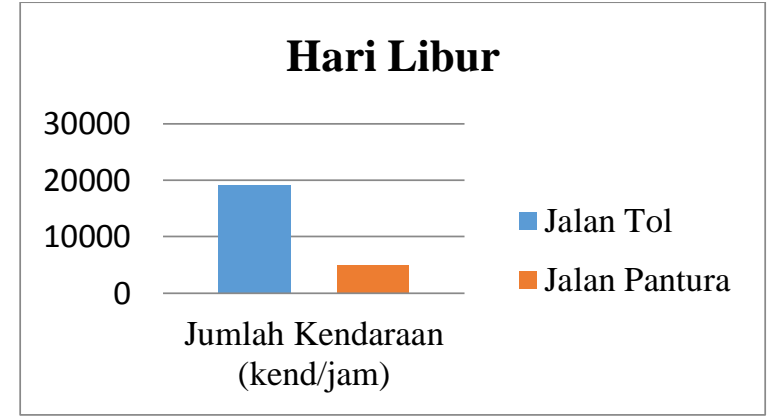

Gambar 6. Grafik Perbandingan Jumlah Kendaraan di Jalan Tol dan Jalan Pantura Pada Hari Libur

Terlihat bahwa jumlah kendaraan yang melewati jalan tol lebih tinggi dari pada jalan pantura dengan presentase kendaraan yang melewati tol adalah $79,55 \%$ dihitung dari jumlah kendaraan yang lewat jalan tol (19.143 kend/jam) dibagi penjumlahan kendaraan yang lewat jalan tol ditambah kendaraan yang lewat jalan pantura $(4.920 \mathrm{kend} / \mathrm{jam})$. Sedangkan presentase kendaraan yang melewati jalan pantura adalah $20,45 \%$. Kendaraan yang melewati jalan tol didominasi oleh kendaraan Golongan I yaitu mobil pribadi, pick up dan bus.

Berdasarkan grafik diatas dapat diketahui bahwa jumlah kendaraan yang melewati Jalan Tol TegalPemalang pada hari kerja dan hari libur lebih tinggi dari pada Jalan Pantura Tegal-Pemalang pada hari kerja dan hari libur.

\section{Prediksi Tingkat Pertumbuhan Lalu Lintas Jalan Pantura Selama 10 Tahun Mendatang}

Produk Domestik Regional Bruto (PDRB) digunakan untuk menentukan nilai pertumbuhan lalu lintas (i) yang dianalisa berdasarkan banyak pertimbangan antara lain berdasar pertumbuhan PDRB Tegal, PDRB Pemalang dan pertumbuhan penduduk Provinsi Jawa Tengah. Hal ini didasarkan pada lokasi Jalan Tol Tegal-Pemalang yang berada pada provinsi Jawa Tengah.

Tabel 5. Perediksi 10 Tahun Arah Tegal

\begin{tabular}{cccccccccc}
\hline Th & LV & MHV & LB & LT & MC & $\begin{array}{c}\text { Total } \\
\text { (smp/ }\end{array}$ & C & DS & LOS \\
\hline 2019 & 384 & 218,4 & 25,5 & 446 & 625,5 & 1699,4 & 1824 & 0,93 & D \\
2020 & 419,71 & 238,71 & 27,87 & 487,48 & 683,67 & 1857,44 & 1824 & 1,02 & E \\
2021 & 458,75 & 260,91 & 30,464 & 532,81 & 747,25 & 2030,19 & 1824 & 1,11 & F \\
2022 & 501,41 & 285,18 & 33,297 & 582,37 & 816,75 & 2219 & 1824 & 1,22 & F \\
2023 & 548,04 & 311,7 & 36,39 & 636,53 & 892,705 & 2425,36 & 1824 & 1,33 & F \\
2024 & 599,01 & 340,69 & 39,78 & 695,72 & 975,73 & 2650,92 & 1824 & 1,45 & F \\
2025 & 654,72 & 372,37 & 43,48 & 760,42 & 1066,47 & 2897,45 & 1824 & 1,59 & F \\
2026 & 715,60 & 407 & 47,52 & 831,14 & 1165,65 & 3166,92 & 1824 & 1,74 & F \\
2027 & 782,15 & 444,85 & 51,94 & 908,44 & 1274,06 & 3461,44 & 1824 & 1,9 & F \\
2028 & 854,9 & 486,22 & 56,77 & 992,92 & 1392,54 & 3783,35 & 1824 & 2,07 & F \\
2029 & 1129,07 & 474,5 & 171,55 & 661,87 & 1829,87 & 4135,21 & 1824 & 2,27 & F \\
\hline
\end{tabular}




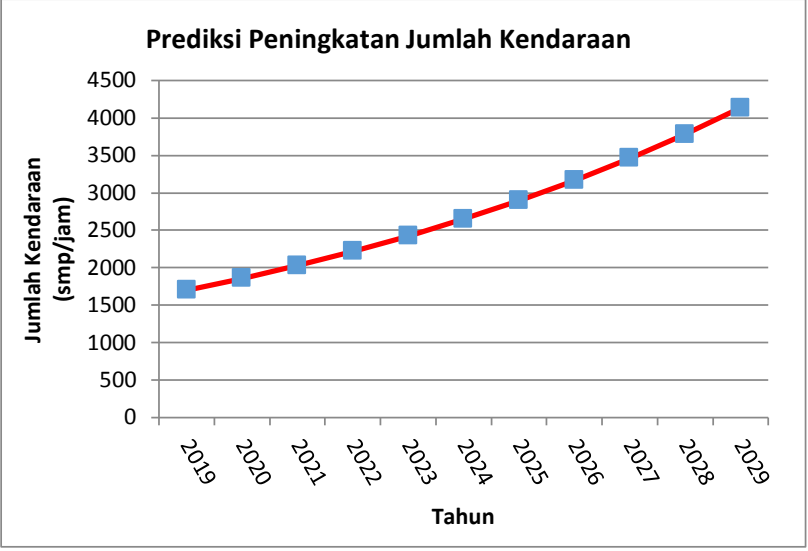

Gambar 7. Grafik Pertumbuhan Kendaraan Arah Tegal

Menunjukkan grafik pertumbuhan kendaraan pada Jalan Pantura Arah Tegal mulai tahun 2019 hingga tahun 2029. Pada tahun 2019 dapat diketahui bahwa jumlah kendaraan adalah 1753,5 smp/jam dan memiliki derajat kejenuhan sebesar 0,96 , sehingga tingkat pelayanan dari Arah Tegal pada tahun 2019 adalah E. Setiap tahunnya jumlah kendaraan yang melewati Arah Tegal terus mengalami peningkatan dengan kapasitas jalan yang tetap sehingga derajat kejenuhannya meningkat yang menyebabkan tingkat pelayanan semakin menurun yang dibuktikan pada tahun 2029 jumlah kendaraan mencapai 4266,85 smp/jam dengan derajat kejanuhan mencapai 2,33 sehingga tingkat pelayanannya bernilai $\mathrm{F}$. Hal ini menunjukkan bahwa tingkat pelayanan pada tahun 2029 mengalami penurunan.

Tabel 6. Perediksi 10 Tahun Arah Pemalang

\begin{tabular}{cccccccccc}
\hline Th & LV & MHV & LB & LT & MC & $\begin{array}{c}\text { Total } \\
(\mathbf{s m p} / \\
\text { jam })\end{array}$ & C & DS & LOS \\
\hline 2019 & 464 & 195 & 70,5 & 272 & 752 & 1753,5 & 1824 & 0,96 & E \\
2020 & 507,15 & 213,14 & 77,06 & 297,3 & 821,94 & 1916,58 & 1824 & 1,00 & E \\
2021 & 554,31 & 232,96 & 84,22 & 324,94 & 898,38 & 2094,82 & 1824 & 1,14 & F \\
2022 & 605,87 & 254,62 & 92,06 & 355,16 & 981,93 & 2289,64 & 1824 & 1,25 & F \\
2023 & 662,21 & 278,30 & 100,62 & 388,19 & 1073,24 & 2502,57 & 1824 & 1,37 & F \\
2024 & 723,80 & 304,18 & 109,97 & 424,3 & 1173,06 & 2735,31 & 1824 & 1,49 & F \\
2025 & 791,11 & 332,47 & 120,20 & 463,76 & 1282,15 & 2989,69 & 1824 & 1,63 & F \\
2026 & 864,69 & 363,39 & 131,38 & 506,89 & 1401,39 & 3267,74 & 1824 & 1,79 & F \\
2027 & 945,10 & 397,19 & 143,6 & 554,03 & 1531,72 & 3571,64 & 1824 & 1,95 & F \\
2028 & 1033 & 434,13 & 156,95 & 605,55 & 1674,17 & 3903,8 & 1824 & 2,14 & F \\
2029 & 1129,07 & 474,5 & 171,55 & 661,87 & 1829,87 & 4266,85 & 1824 & 2,33 & F \\
\hline
\end{tabular}

Gambar 8. Grafik Pertumbuhan Kendaraan Arah Pemalang

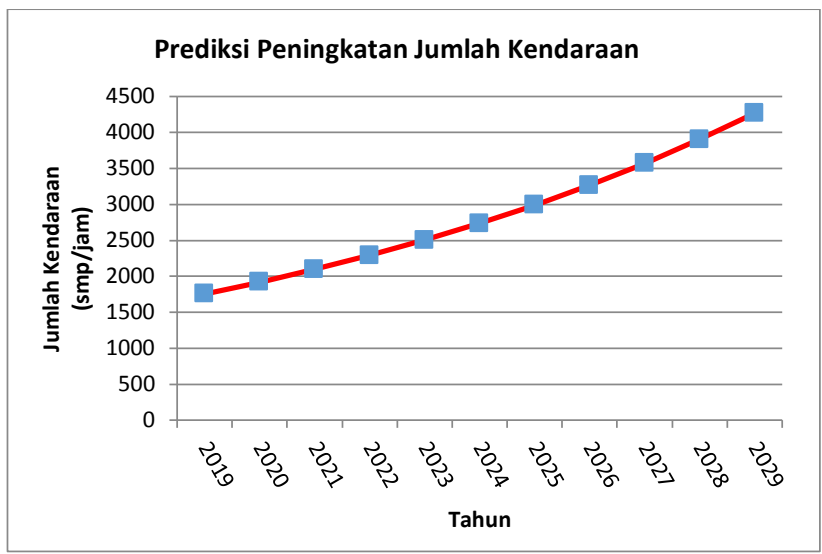

Menunjukkan grafik pertumbuhan kendaraan pada Jalan Pantura Arah Pemalang mulai tahun 2019 hingga tahun 2029. Pada tahun 2019 dapat diketahui bahwa jumlah kendaraan adalah 1699,4 smp/jam dan memiliki derajat kejenuhan sebesar 0,93, sehingga tingkat pelayanan dari Arah Pemalang pada tahun 2019 adalah D. Setiap tahunnya jumlah kendaraan yang melewati Arah Pemalang terus mengalami peningkatan dengan kapasitas jalan yang tetap sehingga derajat kejenuhannya meningkat yang menyebabkan tingkat pelayanan semakin menurun yang dibuktikan pada tahun 2029 jumlah kendaraan mencapai 4135,21 smp/jam dengan derajat kejanuhan mencapai 2,27 sehingga tingkat pelayanannya bernilai $\mathrm{F}$. Hal ini menunjukkan bahwa tingkat pelayanan pada tahun 2029 mengalami penurunan.

\section{Kesimpulan}

Berdasarkan penelitian yang telah dilakukan dapat diperoleh kesimpulan bahwa kinerja lalu lintas Jalan Pantura Tegal-Pemalang sebelum adanya Jalan Tol Tegal-Pemalang memiliki tingkat pelayanan yang mencapai level $\mathrm{F}$ dimana kondisi arus lalu lintas terhambat, kecepatan rendah, volume diatas kapasitas dan banyak berhenti. Sedangkan setelah adanya jalan tol, tingkat pelayanan jalan pantura arah Tegal menjadi level E dan arah Pemalang menjadi level D. Artinya setelah beroperasinya jalan Tol Tegal-Pemalang kinerja lalu lintas jalan Pantura Tegal-Pemalang mengalami penurunan namun tidak signifikan. Hal ini dapat dilihat dari data nilai derajat kejenuhan sebelum adanya tol arah Tegal sebesar 1,26 dan arah Pemalang sebesar 1,23. Setelah adanya jalan tol nilai derajat kejenuhan arah Tegal berubah menjadi 0,96 dan arah Pemalang menjadi 0,93. Kendaraan yang melewati Jalan Tol Tegal-Pemalang pada hari kerja adalah 79,35\% dan pada hari libur 79,55\% sehingga dapat disimpulkan bahwa pada hari libur kendaraan yang melewati jalan tol memiliki presentasi lebih banyak bila dibandingkan dengan hari kerja, sedangkan kendaraan yang melewati 
Jalan Pantura Tegal-Pemalang pada hari kerja memiliki presentase lebih banyak dibanding hari libur yaitu hari kerja 20,65\% dan hari libur $20,45 \%$. Secara keseluruhan presentasi kendaraan yang melewati jalan pantura memilliki presentase lebih sedikit dibandingkan kendaraan yang melewati jalan tol. Tingkat pertumbuhan lalu lintas Jalan Pantura Tegal-Pemalang berdasarkan Produk Domestik Regional Bruto (PDRB) selama 10 tahun mendatang terus mengalami peningkatan. Total kendaraan arah Tegal pada tahun 2019 sebesar 1753,5 smp/jam memiliki tingkat pelayanan E sedangkan pada tahun 2029 total kendaraan sebesar 4266,85 smp/jam yang memiliki tingkat pelayanan F. Untuk total kendaraan arah Pemalang pada tahun 2019 sebesar 1699,4 smp/jam memiliki tingkat pelayanan D sedangkan pada tahun 2029 total kendaraan sebesar 4135,21 smp/jam yang memiliki tingkat pelayanan $\mathrm{F}$.

\section{Daftar Pustaka}

Anonim. 2019. Jalan Pantura Tegal-Pemalang. http://id.m.wikipedia.org (diakses 28 Februari 2019)

Badan Pusat Statistik Jawa Tengah. 2019. PDRB Jawa Tengah Atas Dasar Harga Berlaku Menurut Lapangan Usaha Juta Rupiah 20102018. https://jateng.bps.go.id/ (diakses 23 Maret 2019)

Departemen Pekerjaan Umum. 1997. Manual Kapasitas Jalan Indonesia. Direktorat Jenderal Bina Marga, Jakarta.

Dinas Perhubungan Kabupaten Tegal. 2017. Buku Kinerja Keselamatan Tramsportasi Jalan Kabupaten Tegal. Tegal

Google Inc. 2019. Google Image: Lokasi Jalan Pantura Tegal-Pemalang. http://maps.google.com/ (diakses 28 Februari 2019)

Kementrian Perhubungan. 2006. Keputusan Menteri Perhubungan No 14 Tahun 2006 tentang Manajemen dan Rekayasa Lalu Lintas di Jalan. Jakarta.

Kementrian Perhubungan. 2015. Peraturan Menteri Perhubungan No 96 Tahun 2015 tentang Pedoman Pelaksanaan Kegiatan Manajemen dan Rekayasa Lalu Lintas. Jakarta.

Keputusan Menteri Pekerjaan Umum Nomor 370/KPTS/M/2007. 2007. Penetapan Golongan Jenis Kendaraan Bermotor Pada Ruas Jalan Tol. Jakarta.

Nugroho, Untoro dkk. 2017. Evaluasi Kapasitas Ruas Jalan Pantura Kabupaten Brebes. Universitas Negeri Semarang. Jurnal Teknik Sipil \& Perencanaan, 19(1), 71-76.

PT. Pejagan Pemalang Toll Road (PPTR). 2019. LHR Pintu Tol Tegal 2018-2019 \& Tipikal Cross Section Tegal-Pemalang. Tegal
Rachmawati, Annisa dkk. 2014. Evaluasi Dan Pemecahan Masalah Lalu Lintas Pada Ruas Jalan Pantura Di Kabupaten Rembang (Kaliori-Sluke). Universitas Diponegoro. Jurnal Karya Teknik Sipil, 4(3), 1005-1014.

Rusdiono, Tri Angga Prakoso dkk. 2016. Evaluasi Kinerja Lalu Lintas Ruas Jalan PandaanGempol Sebelum Dan Sesudah Adanya Jalan Tol. Universitas Brawijaya. Malang. Vol. 1 No. 2

Sugiyono. 2008. Metode Penelitian Kuantitatif Kualitatif Dan R\&D. Bandung: Alfabeta.

Undang-undang Nomor 38 Tahun 2004. Tentang Jalan, Departemen Pekerjaan Umum. Jakarta.

Wahab, Wahyuni dkk. 2015. Analisis Nilai Pertumbuhan Lalu Lintas Dan Perkiraan Volume Lalu Lintas Dimasa Mendatang Berdasarkan Volume Lalu Lintas Harian Rata-Rata (Studi Kasus Ruas Jalan SP.LagoSorek/ Jalan Lintas Timur). Universitas Riau. JOM FTEKNIK. Vol. 2 No. 1 